\title{
A Coordinated Effort to Improve Parameterization of High-Latitude Cloud and Radiation Processes
}

\author{
J. O. Pinto \\ A.H. Lynch \\ University of Colorado
}

\section{Scientific Goals:}

The goal of this project is the development and evaluation of improved parameterization of arctic cloud and radiation processes and implementation of the parameterizations into a climate model. Our research focuses specifically on the following issues:

- continued development and evaluation of cloud microphysical parameterizations, focusing on issues of particular relevance for mixed phase clouds,

- evaluation of the mesoscale simulation of arctic cloud system life cycles.

\section{Research summary:}

- Evaluation of mesoscale simulation of arctic cloud system life cycles in the context of the Arctic Regional Climate Model Intercomparison Project (ARCMIP). Assembly of two different gridded and co-located high-resolution satellite data sets of cloud/radiation properties during the SHEBA year has been completed (under NASA funding). These two data sets have been evaluated against the surface-based observations during SHEBA and an EOF analysis has been done to interpret the horizontal variability of the cloud and surface radiation fluxes determined from satellite and also the NWP analyses (Liu et al.). The output of 7 different mesoscale models has been submitted to ARCMIP. The model intercomparison and evaluation of simulated cloud and radiation properties over SHEBA has been conducted, with a journal paper in final stages of preparation (Inoue et al.).

- A new five-class double-moment bulk microphysics scheme has been developed for use in mesoscale and climate models that predicts the hydrometeor number concentration and mixing ratio (Morrison et al). This scheme incorporates many of the theoretical developments made by Khvorostyanov et al.; see below. In particular, these parameterizations allow for explicit treatment of cloud-aerosol interaction for ice, liquid, and mixed-phase clouds. The new scheme as been extensively evaluated against observations obtained during SHEBA and at the ARM CART site at Barrow using a SCM. It was then incorporated into the PSU/NCAR mesoscale model (MM5). Results using the new scheme were compared to parallel simulations using other microphysics schemes that are publicly available in MM5. The predicted cloud phase and liquid water path are significantly 
improved using the new scheme relative to a single-moment scheme predicting only the mixing ratios of the water species. The more detailed treatment of ice nucleation processes in the new scheme also improved prediction of cloud phase and water content relative to a double-moment scheme predicting ice crystal number concentration. Sensitivity tests were performed by varying the aerosol solubility, size, and number concentration using the SCM and MM5. Model results exhibited large sensitivity to the aerosol characteristics. These results suggest that detailed treatment of cloud-cloud processes, particularly crystal concentration and ice nucleation, is needed to adequately simulate the observed mixed-phase stratus.

- Our new theory of heterogeneous ice nucleation was incorporated into a parcel model with explicit water and ice microphysics to simulate the process of ice nucleation under transient thermodynamic conditions. It is shown that: a) the same cloud condensation nuclei $(\mathrm{CCN})$ are responsible for the drop and crystal nucleation and can be identified as ice nuclei (IN) when crystals form; b) the nucleation rates and concentrations of nucleated crystals depend on temperature and supersaturation simultaneously; c) the new theory yields reasonable crystal concentrations over the entire temperature range for all tested initial conditions and vertical velocities; d) the kinetics of heterogeneous ice nucleation exhibits a negative feedback regulated via water supersaturation. A comparison with chamber and field measurements shows general agreement; potential reasons of discrepancies are discussed along with the possible ways of theory verification and application. Based on these calculations, a simple parameterization for ice nucleation is suggested for use in bulk cloud models and large-scale models.

- We have continued to evaluate both the explicit microphysics model and bulk microphysics parameterization against observations. We have continued to focus on the SHEBA data set, owing to the tremendous effort that has gone into quality control on this data. We have also begun evaluating the models against tropical clouds from CRYSTAL FACE. We had a small amount of CRYSTAL FACE funding from NASA, but this work is now being continued under our ARM funding. We view the evaluation of our models and parameterizations in different cloud types and regions using both SCMs and mesoscale models as an essential element of eventually having our parameterizations incorporated into GCMs. 


\section{Plans for Year 3:}

MPACE. Our group has participated extensively in the planning for MPACE. We will be participating in the field experiment in conjunction with our NSF Aerosonde grant to make observations of temperature, humidity, pressure, winds, aerosols, ice particles, and ozone. We intend to be actively involved in the data analysis and we also plan to conduct a suite of modeling studies including single column, cloud resolving, and mesoscale models, with both bin and bulk microphysics.

Theoretical microphysics. We are continuing our theoretical research on heterogeneous ice nucleation. Our current theories (on deliquescence freezing) will be extended to included contact and immersion nucleation. We intend to use the explicit microphysics model to further explore the appropriate microphysical treatments for mixed phase clouds. We are also in the process of revising our ice crystal fall velocity parameterization to account for recent field and laboratory data. We are also using our previous work on stochastic condensation in clouds (Khvorostyanov and Curry, JAS, 1999) and the explicit microphysics model to develop a parameterization for ice crystal size distributions that allow to express them via the quantities measured by aircraft or produced by the cloud bulk models, to account for the temperature dependence of the spectra and are capable of producing the bimodal spectra. We have also begun development of a new drop activation scheme that is an extension of our previous work (Khvorostyanov and Curry, J. Geophys. Res., 1999), allowing a quasi-power law representation of any aerosol size spectra and CCN activity spectra, is capable of reproducing laboratory data on drop nucleation in the wide range of supersaturations up to of $10 \%$, and can be used in both bin and bulk models.

Continued development and evaluation of bulk microphysics parameterizations. The new bulk microphysics scheme will continue to be evaluated and improved for incorporation into NWP and climate models. Further evaluation will be done using data collected during MPACE IOP. These evaluations will rely heavily on both in situ measurements and the remotely sensed measurements obtained at the Barrow ARM cart site. Improvements to the bulk model will include a more detailed treatment of several microphysical processes and increased efficiency. We will continue to develop and incorporate new parameterizations based upon theoretical microphysics, explicit microphysics modeling and observations, particularly the treatment of ice-phase processes. This will include treatments of particle fallspeeds, particle habits, and the shape of the ice particle size spectra. We will also focus on improving the parameterization of interactions between the sub-gridscale dynamics and microphysics, which are crucial in predicting droplet and crystal nucleation and hence number concentration. The scheme will be made more efficient with the continued development of lookup tables. Sensitivity testing will be used to determine which areas of the scheme can be reduced in complexity (e.g., reducing the number of prognostic variables) to further improve efficiency. 


\section{Refereed publications since 2003}

Randall., D., S. Krueger, C. Bretherton, J.A. Curry, et al., 2003: Confronting Models with Data: The GEWEX Cloud System Study. Bull. Amer. Meteor. Soc., 84, 455-469

Khvorostyanov, V.I., J.A. Curry, I. Gultepe, 2003: Simulations and observations of springtime cloud over the Cape Bathurst polynya. J. Geophys. Res., 108 Art. No. 4296

Morison, H., M. Shupe, J.A. Curry, 2003: Evaluation of a bulk microphysical scheme using SHEBA data. J. Geophys. Res., 108, art no. 4225.

Morrison, H. and J.O. Pinto, A new approach for obtaining advection profiles: Application to the SHEBA column. Mon. Wea. Rev., 132, 687-702.

Khvorostyanov, V.I. and J.A. Curry, 2004: Theory of heterogeneous ice nucleation. Part I: Critical radius, energy and nucleation rate. J. Atmos. Sci., in press

Khvorostyanov, V.I. and J.A. Curry, 2004: Theory of heterogeneous ice nucleation. Part II: Parcel model simulations. J. Atmos. Sci., in press

Khvorostyanov, V.I. and J.A. Curry, 2004: On the Thermodynamic Theory of Freezing and Melting of Water and its Solutions: J. Phys. Chem. A, accepted.

Inoue, J., B. Kosovic and J.A. Curry, 2004: Evolution of a storm-driven boundary layer in the Arctic. Bound. Layer Meteorol., accepted.

Morrison, H., J.A. Curry, V.I. Khvorostyanov, 2004: A new double-moment microphysics parameterization. Part 1: Description. J. Atmos. Sci., accepted.

Morrison, H. J.A. Curry, M. Shupe, P. Zuidema, 2004: A new double-moment microphysics parameterization. Part 2: Application to Arctic stratiform clouds. J. Atmos. Sci., provisionally accepted.

Khvorostyanov, V.I., H. Morrison, J.A. Curry, D. Baumgardner, and P. Lawson, High supersaturation and modes of ice nucleation in thin tropopause cirrus: Simulation of the 13 July 2002 CRYSTAL case. J. Geophys. Res., submitted

Inoue, J., J. Liu and J. A. Curry, 2004: Intercomparison of Arctic regional climate models for the May 1998 period of SHEBA, J. Climate (to be submitted Nov 2004)

Morrison, H., and J. O. Pinto, 2004b: Mesoscale modeling of arctic mixed-phase stratus using a two-moment bulk microphysics scheme, to be submitted to J. Atmos. Sci.

Morrison, H., and J.O. Pinto, 2004c: A comparison of different cloud microphysics schemes in mesoscale simulations of arctic mixed-phase stratus, to be submitted to Mon. Wea. Rev.

Morrison, H. and J.O. Pinto, 2004d: Mesoscale modeling of arctic mixed-phase stratus: Sensitivity to surface conditions and aerosol characteristics, to be submited to $J$. Atmos. Sci.

\section{Recent related publications funded primarily by other sources:}

Inoue, J., J.A. Maslanik, and J.A. Curry, 2004: Application of Aerosondes to highresolution observations of sea surface temperature over Barrow Canyon. Geophys. Res. Lett., submitted

Liu, J., J.A. Curry, and Y. Hu, 2004: Recent Arctic sea ice variability: Connections to the Arctic Oscillation and the ENSO. Geophys. Res. Lett, submitted.

Lynch, A.H., J.A. Curry, R.D. Brunner, J.A. Maslanik, 2004: Towards an integrated assessment of the impacts of extreme wind events on Barrow, Alaska. Bull. Amer. Meteor. Soc, 85, 209-221.

Mirocha, J.D., B. Kosovic, and J.A. Curry, 2004: Vertical heat transfer in the lower atmosphere over the Arctic Ocean during clear sky periods. Bound. Layer Meteorol., submitted.

Curry, J.A., J.M. Maslanik, G.J. Holland, and J.O. Pinto, 2004: Applications of Aerosondes in the Arctic. Bull. Amer. Meteorol. Soc., in press.

Mirocha, J., B. Kosovic, and J.A. Curry, 2004: Evaluation of Planetary Boundary Layer schemes in the Arctic during clear-sky conditions. Bound. Layer Meteorol., in press. 
Liu, J., J.A. Curry, W. B. Rossow, J.R. Key, X. Wang, 2004: Comparison of surface radiative flux data sets over the Arctic Ocean. J. Geophys. Res., accepted.

Rinke, A., K. Dethloff, J. Cassano, J.H. Christensen, J.A. Curry, and 11 others, 2004: Evaluation of an ensemble of arctic regional climate models: spatial patterns and height profiles. J. Climate, provisionally accepted. 